\title{
Rising to the occasion: Exploring the changing emphasis on educational design during COVID-19
}

\author{
Amanda Bellaby \\ Queensland University of Technology \\ Australia
}

\author{
Michael Sankey \\ Griffith University \\ Australia
}

\author{
Louis Albert \\ Griffith University \\ Australia
}

\begin{abstract}
With the advent of COVID-19, the majority of universities in Australasia have had to adjust quickly to provide the bulk of their learning and teaching activities online. To a great extent this involved learning/educational designers (and titles similar to this) needing to provide a range of tasks (some new) associated with supporting many teaching staff unfamiliar with teaching online. In some cases, this has meant a change in role, while for others it was transitioning to new and higher levels of responsibility. Regardless, the emotional impact of this should not be understated, or at least should understood. This paper explores these concepts based on the feedback from 90 educational designers, mainly from the Australasian higher education sector. It presents details of the results of a semi-structured qualitative study of those working in the field of educational design at universities. These designers were asked to consider how COVID-19 has impacted the ways in which they undertook their work, the types of issues they are dealing with, and the solutions they were proposing and contributing. Their accounts document the changing nature of their roles and their emotions in the face of potentially unalterable changes.
\end{abstract}

Keywords: COVID-19, online learning, educational design, technology enhanced learning.

\section{Introduction}

Prior to the onset and ramifications of COVID-19, the higher education sector recognised educational design as an area of professional expertise and one that has seen increased growth (Nicholas \& Meuleman, 2017). Those practising educational design have been shown to assume several diverse responsibilities inclusive of course design, academic mentorship and collaboration, project management and educational research (Brown et al., 2020). In recent times, they have acquired increased attention due to their expertise in online learning. This is particularly evident during the current epidemiological crisis that has forced mass closures of tertiary institutions across the globe. In response, learning and teaching has rapidly transitioned to online domains in a way that has been described as an "emergency measure" (Pevneva \& Edmunds, 2020, p. 1). Whilst the sector is becoming increasingly aware of the increased workload, unrelenting pressures and added stresses experienced by academic staff who are struggling to move online (Houlden \& Veletsianos 2019), less understood is how educational designers are currently being impacted by this change.

Considering that one of the key challenges for teaching staff, in many cases, is their lack of knowledge of the pedagogical principles needed to design and facilitate online learning (Ching, Hsu, \& Baldwin, 2018; Rapanta et al., 2020), the role of the educational designer is even more in demand. As advocated by Watermeyer et al., (2020), there is a need "to take the pulse of universities" (p. 2) that is inclusive of, but goes beyond the perspective of academics, to those who support these important roles.

As a means to provide insights into the ways educational designers are dealing with the day-to-day implications of adjusting to the changes brought about by COVID-19, the present article details the results of a semistructured qualitative study of those working in the field of educational design at universities. This study considers this has impacted the ways they complete their work, the types of issues they are dealing with, and the solutions they are proposing and contributing. Their accounts document the changing nature of their role and the emotional challenges they face in doing so, particularly in the face of potentially unalterable circumstances. 


\section{Literature review}

\section{The educational designer in higher education}

Despite the position initially considered a novelty, the number of educational designers in higher education are increasing (Bissett, 2018). These positions and their corresponding occupational titles vary across institutions but are typically associated with integrating pedagogical theories with emerging technologies through course design (Bissett, 2018) and are now consistently recognised as being "crucial in supporting academics" (Seeto \& Herrington, 2006, p. 741). Professionals in educational design are situated in a transdisciplinary field and constantly navigate between "the technical and pedagogical" (Bisset, 2018, p. 71) in collaborative and ambiguous contexts. Given their diverse professional backgrounds and career pathways, many attempt to "draw on institutional culture, professional literature, professional organisations and reflection to understand their boundaries of practice" (Shwier, Campbell, \& Kenny, 2004, p. 77). Similarly, the role may be defined and informed by organisational priorities, pressures and changes, which can leave the professional identity of these roles somewhat ill-defined, ambiguous and subject to constant change (Bisset, 2018).

Even prior to the COVID-19 crisis, the role of educational designers was evolving, linked closely to the increased role that technology now plays in educational practice, such that North (2019) deemed designers to be more critical than ever in helping to respond to a technologically ubiquitous society. This has meant some educational designers have been regarded as techies and are, subsequently, relied on for technological support (Ritzhaupt \& Kumar, 2015). Bisset (2018) corroborates this by explaining that, in the past, many educational designers were employed by dedicated production teams and operated in technology support positions as a means to provide "content-focused approached to curriculum development ... that resulted in a mediated experience for academic staff with teaching technologies" (p. 2). Despite this, Bissett (2018) goes on to suggest that, more recently, the role is largely focused on supporting sustainable practice, building staff capability to navigate their own use of digital technologies to enhance their teaching. Thus, educational designers may help to shape organisational discourse about what learning actually means. Despite occupying this important space, numerous educational designers have reportedly felt marginalised, misunderstood and devalued by academic staff (Ritzhaupt \& Kumar, 2015). They have struggled to collaborate with academics who have expressed concerns about the perceived inferiority of online learning and that students amount to nothing more than numbers during the design process as learning is seemingly mechanised (Berrett, 2016).

In anticipating the future of learning and teaching, the 2020 Horizon Reports (Brown et al., 2020) identified the field of educational design as one of the most influential trends shaping higher education due to an increased interest in and desire for online learning and student-centred learning environments. This report emphasises the changing nature of instructional design, noting that the role has grown beyond "standard course design and development" (Brown et al., 2020, p. 23) to become more inclusive of responsibilities such as mentorship, educational research, project management and learning analytics. Thus, those within the interdisciplinary ecosystem are thought to be agents of change at the personal, relational and institutional levels (North, 2019) and are well positioned to have significant impact. Earlier, Conole and Wills (2013) had declared, "designing for learning is arguably the key challenge facing education today" (p. 24). Such assessments may have been unwittingly prophetic with the onset of COVID-19 requiring new ways of thinking and working as a means to respond to the disruptive challenges facing learning and teaching at tertiary institutions.

\section{COVID-19 and the consequences for higher education}

From its initial emergence, COVID-19 quickly generated far-reaching economic and societal impacts. For those working in an educational context, this impact has been lockdown and the enforced closure of schools, colleges and universities (Watermeyer et al., 2020). In response, institutions were bound to transition and scale up online teaching to ensure that learning would not be completely disrupted (Burki, 2020). This migration seemingly happened overnight (Dhawan, 2020) and has, consequently, mostly been characterised as adventitious, rapid and incipient (Johnson, Veletsianos, \& Seaman, 2020). As described by Tesar (2020), every course moved online in a matter of days whether or not staff had any online teaching experience. For many, the headlong thrust into providing learning experiences for students via a digital interface has been confusing, unfamiliar and unwanted (Johnson et al., 2020; Watermeyer et al., 2020). Some experienced discomfort and anxiety not only due to the technology but also from being forced to employ new pedagogical techniques at a moment's notice (Johnson et al., 2020). Such a transition to emergency remote learning and teaching has provided fodder for previous critiques that online learning has not been extensively thought through and has received only "minimal 
meaningful investment" (Tesar, 2020, p. 557). Findings from Watermeyer et al., (2020) survey of over a thousand academics working in universities in the United Kingdom revealed that they had been wounded from engaging with emergency online transition and, subsequently, become disillusioned and distrustful "of a more prolonged and substantial embrace of digital pedagogies by their institution" (p. 14). Concerns have also been expressed about how it is possible that courses can offer the same opportunities and learning outcomes online as on-campus (Fawns, Jones, \& Aitken, 2020). However, some have adopted more optimistic tones arguing that higher education has long been "overdue for a complete overhaul" (Watermeyer et al., 2020, p. 14). Other worries have legitimately centred around the mental health of students given that studying online may be an isolating experience and that they may be unable to access support structures (Fawns et al., 2020; Fazackerley, 2020). Unsurprisingly, several have cited an increased and more intense workload as they accommodate an escalation in the pastoral needs of students and as their personal and professional lives blur together whilst working from home (Kirk, 2020). In surveying close to 900 faculty and administrators at various institutions in the United States, Johnson et al., (2020) determined that most desire substantial information and guidance on best practices related to online teaching, providing weight to the suggestion by Watermeyer et al., (2020) that in the rush to perform online migration of courses academics are employing "entry-level" digital pedagogies (p. 1). Consequently, whilst the pandemic has accelerated the inevitability of a widespread adoption of online learning, there exists a concern that the rapid response to online may have resulted in prejudicial and distorted views of digital pedagogies from the academic community to the extent to which any future changes to their roles will "be viewed only through the lens of precarisation" (Watermeyer et al., 2020, p. 15).

Whilst Doucet et al., (2020) argue there is no precedent to offer guidance during the pandemic, this assessment is not entirely accurate. Transferring education online during times of disruption is not a new phenomenon and previous events provide important lessons (Ayebi-Arthur, 2017; Czerniewicz, Trotter, \& Haupt, 2019). Baytiyeh (2018), in determining the critical role of technologies in supporting education delivery during temporary closures after natural disasters, found that technology helped to empower students and enable a positive learning environment. Todorova and Bjorn-Andersen (2011) proclaimed technology to be instrumental in "pedagogical survival" (p. 599). However, the success of remote online learning during emergencies is dependent on instructors' presence and guidance (Mackey et al., 2012) as well as the quality of technical infrastructure and support (Ayebi-Arthur, 2017). Further, in his assessment on the status of African-American higher education post Hurricane Katrina, Duke (2005) determined that the disaster had produced long-lasting damage not only to African-American students in New Orleans but across the whole nation. This serves as an important reminder that it is often the most vulnerable who will suffer more during times of crisis. It appears that past events may have been treated as isolated and rare occurrences, having little significant bearing on more widespread and institutional approaches to digital strategy or pedagogies. As noted by Lorenzo (2008), despite incidents such as hurricanes, earthquakes and wars taking their toll on universities over the years, "precious little planning seems to have been put into the continuation of teaching and learning in higher education if physical campuses must be closed" (p. 6). However, this is understandable given that COVID-19 demanded a global or at least nationwide transition to online learning as opposed to a regional response (Johnson et al., 2020).

Although the impact of COVID-19 and the emergency migration of online courses is irrefutably seismic, we are merely at the beginning of being able to recognise the full impacts of this on higher education. Indeed, much of the literature is embryonic and mostly relies on speculation to form assertions on the changing nature of the educational landscape and a post-pandemic pedagogy. Nevertheless, it seems safe to surmise that "shift to online learning looks set to continue at least until the advent of a successful vaccine for COVID-19" (Burki, 2020, p. 758). Dhawan (2020) has declared that teaching online is no longer a choice but a necessity, going so far as to optimistically proclaim it a "panacea for the crisis" (p. 3). He (Dhawan, 2020) also cautions that the quality of online courses amidst the crisis will determine an institution's reputation. Watermeyer et el., (2020) similarly speculates that only those institutions that provide a quality online experience will gain market advantage.

There is obviously much uncertainty currently plaguing the educational landscape. However, what we can determine from emerging literature and previous incidents is that, in the midst of significant upheaval and disgruntled staff and students, there is a need for support staff who possess expertise in how students learn. This is affirmed by Johnson at.al., (2020) who recommend equipping academics with the necessary skills and knowhow to effectively teach online. Failure to do so may result in "dumbed-down pedagogy associated with the current emergency online migration" (Watermeyer et al., 2020, p. 16). Czerniewicz et al., (2019) advised that, in a situation of university shutdown, we should also pay attention to the role of educational designers who operate at the nexus between learning and technology. Unfortunately, excluding previous musings, little is known about the ways in which educational designers have adapted and responded to the unfolding crisis. 
Scholarly literature, whilst arguably only providing initial snapshots, has already emerged on how the roles of academics are shifting amidst the online learning migration. Thus, there is a legitimate need to assess the impacts on educational designers given that they regularly collaborate with and support academics in adopting evidence-based pedagogical approaches, employing educational technologies, measuring learning in digital spaces, and designing student-centred activities (Brown et al., 2020). Such expertise will be sorely needed for the success of higher education institutions now and in a post-pandemic world.

\section{Method}

The primary objective of this research was to determine the changing nature of the educational designer role during this unique time and the ways in which these roles (learning designers and related titles) in tertiary institutions are responding to and contributing solutions to the challenges associated with COVID-19. This study is based in a semi-structured qualitative model with a single, open-ended question (Blandford, 2013), asking participants to reflect on their real-life experiences in dealing with their day-to-day work implications. In doing so, they were prompted to consider how COVID-19 has impacted the ways in which they complete their work, the types of issues they were dealing with, and the solutions they were contributing towards.

To achieve these objectives, participants were invited to contribute their insights, thoughts and reflections via an anonymous Microsoft Form housed in the Office 365 tenancy at QUT. The following question was designed to illicit a variety of responses and an understanding of some of the key issues presented by the COVID-19 crisis:

Q: What is your role title and in what ways has your role changed in response to COVID-19? What do you feel you have been able to contribute? Please provide examples where possible.

Although the survey appeared as one question, within that question were three nested questions, initially asking participants to identify their role and then two sub question designed to elicit a more fulsome response from the 90 participants. This was certainly achieved, with an average length of responses being 180 words. This allowed the researchers to identify a broader range of activities being undertaken. In addition to analysing the themes associated with the three questions the 'emotions' being conveyed in the data were also analysed.

The initial recruitment/contact method was via an email to members of the ASCILITE, TEL Edvisors Special Interest Group (SIG). An email was also sent to institutional representatives of ACODE (Australasian Council on Open, Distance and eLearning) to forward onto the design staff at their institutions. The fortnightly

ASCILITE Bulletin was also used to offer members the opportunity to participate. The targeted participant pool included those with roles such as instructional designers, educational designers, learning advisors and others with related titles in tertiary institutions in Australasia. However, as participants were encouraged to share the survey with their colleagues, it was anticipated that some responses would come from outside Australasia. This was seen to be the case, with a small number coming from the UK.

Once collected, the data was coded in Atlast.Ti (https://atlasti.com/) and the result exported to Microsoft Excel to enable basic counts and listing of codes sorted by Respondent ID or by Code. Responses were assigned an ID number so that the coded results could also be sorted by Respondent ID or by Code. The overall framework for coding and analysis of the data was determined by the 3 nested questions. This coding followed a process of assigning a descriptive label or code to a comment or quotation; these text selections ranged from a phrase to several sentences to exemplify the same theoretical or descriptive idea (Gibbs, 2007).

Most responses to Question 2 were assigned 1 of 2 codes relating to 'degree of change' \{significant; not much\}. This code was determined by actual claim made by the respondent or ascribed based on what the description of change amounted to. Each overall response was also ascribed 1 of 5 emotion 'rating' \{negative; a bit negative; neutral; positive; very positive \} based on actual declared sentiments, or on the overall tone of the response. Analysis of the data followed a two-step process. First, after coding half the data, the code book (grouped list of codes with a brief definition) and the interim coding result (codes \& comments) were checked and verified. Subsequently, the full data set was then coded and exported to MS Excel and Word for final reporting.

\section{Analysis and Discussion}

The first part of the question asked participants $(\mathrm{N}=90)$ to identify their role title. 32 respondents $(36 \%)$ had the word 'Designer' in the role title; 6 more had the word 'Design'; 16 respondents (18\%) were 'Learning 
Designers' (or have that phrase in the role title) and 12 respondents identified as Educational Designer. 27 $(30 \%)$ of respondents' title role show that they have management or coordinating responsibilities.

\section{Changes to role}

Sixty-four (71\%) respondents made claims that changes to their role in response to COVID-19 had been very or quite significant (Figure 1). A recent recruit even declared that their role was drastically different to what they had been employed to do. Similarly, 25 (28\%) respondents explained they were now performing duties that were previously only a small part of their work. Some even reported they had actually been redeployed or reassigned. In contrast, others stated that their role had become less strategic in nature and less concentrated:

Normally my role would oversee curriculum and the allocation of learning design support to the School, but COVID has made my role much more responsive. I've been working more with academics individually to support them in solving problems or identifying learning solutions rather than being able to devote time to a whole of course design.

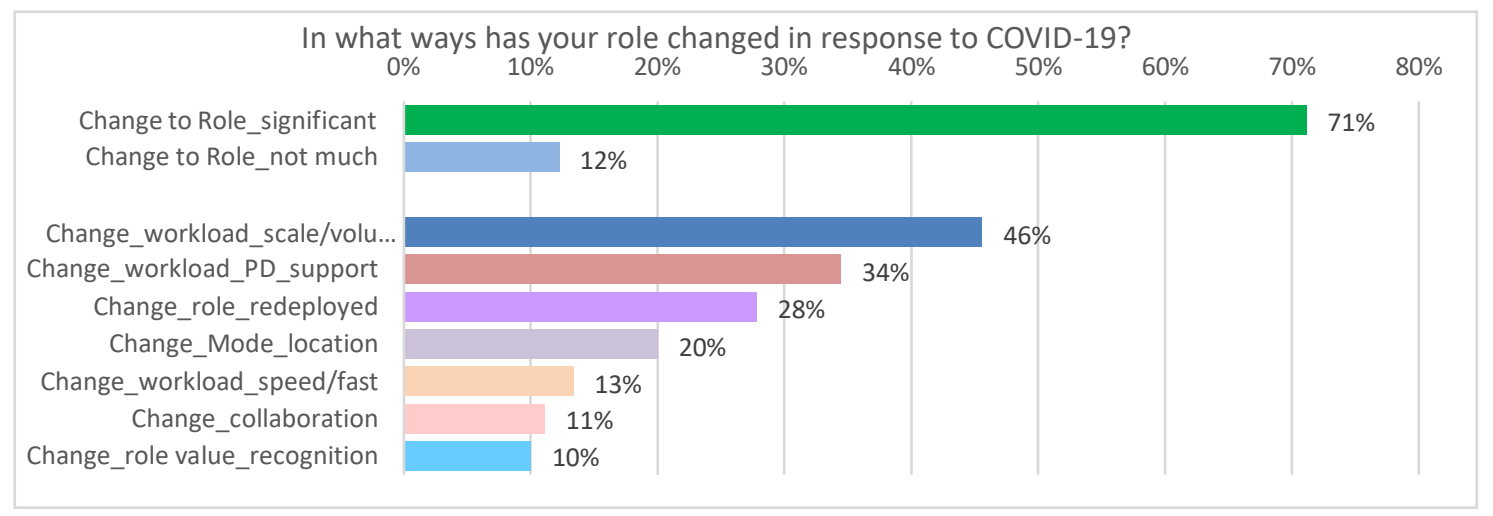

Figure 1. The level and ways roles had changed

Such a change in priorities has eventuated in educational designers taking a more reactive approach and providing just-in-time support for academic staff as they transition to online teaching. One respondent described how they have to be "ready to drop whatever we have been working on to meet the priorities of management at any given time." Consequently, it appeared that educational designers were no longer working with a small number of units and learning initiatives. Rather, they were working on a much wider gamut as they attempt to scale up entire faculties. As such, some reported that their reach has extended, new relationships had been formed and strengthened, and that they were serving a much broader population than prior to COVID-19.

To be able to support a vast number of academic staff who need assistance with the use of specific technologies, the work of educational designers has ranged from individual consultations and responding to email requests to the development of institution-wide policy documents and helpdesk phone rosters. As a means to build online teaching capabilities, educational designers have been busy creating numerous asynchronous and synchronous digital resources. These resources, designed to enable the conversion to online teaching, include webinars, online workshops, educational development courses, instructions on how to use particular technologies, guidelines on online pedagogies, advice on academic integrity, newsletters, tip sheets, blog posts, instructional videos and so on. Several respondents surmised the type of work currently being conducted:

I am ... working on an internal website (Sharepoint) which provides how-to guides for academics. I have created numerous videos and other guides, and leveraged resources crated by others." And "I developed a self-paced online course in "minimum online presence", ran workshops for a wide range of staff groups in how to address a range of design challenges associated with 'emergency online teaching', consulted with staff one-on-one to help with skills or design issues, helped to organise and staff daily online dropin "ask me anything" sessions for staff, and assisted with the development of a range of other resources and materials to support staff...

Some respondents explained that this kind of support is not normally provided by educational designers and commented that they do not normally listen nor respond to technical issues. However, the scope and mass of 
support requests demanded and necessitated an all-hands-on-deck approach.

Not all respondents detailed a significant change in role. Rather, many characterised it as a sharp increase in workload. Even those $(n=11)$ who stated that their role has not essentially changed explained that the scale and volume of their work had amplified to an extent not experienced before. Many spoke about key strategic projects that would normally take months to develop now had to be created in a matter of days, for example:

[I'm] involved in multiple large-scale projects at once, projects that each would normally take $6-12$ months are expected to be completed in one month or less." And "[I've] delivered a year's worth of training (attendances) in 1 week.

Such comments clearly represent the increase in working pace and intensity of the demand. Whilst the essential nature of their role has not changed, the volume and pace of work has certainly ramped up to unprecedented levels. Some painted particularly harrowing tales of working 18-hour days with no overtime or time in lieu since the start of the pandemic, raising legitimate questions regarding increased stress levels. Others explained that whilst their roles have not altered in response to COVID-19, and that they are still supporting academics with teaching and learning, how they are achieving this has shifted. Several respondents detailed how they need and are expected to work at a much faster pace in response to problems that have arisen at short notice. Further, the ways in which educational designers are communicating and collaborating with academics has now transitioned from formerly impromptu exchanges to direct and intentional exchanges, for example:

[Working with academics] has moved from collegiality and 'getting together' informally (and when needed formally) to one which now requires me to nearly always formally organise and create meeting invites - no longer do I get to have corridor conversations with academics over a quick coffee in the kitchen, or a catch up informally after a meeting. Now it is structured into meetings online, lengthy emails that need to be explained with screen grabs, and phone conversations which sometimes need to be quick and to the point.

Although many respondents stated that a great deal of support has been one-on-one, much of the increased workload has been attributed to an increase in the amount of professional development and training developed for and offered to academic staff online. These training sessions were focused particularly on using platforms such as Zoom and Microsoft Teams but also in aspects of online teaching and learning:

...when the campuses shut down and everyone moved online, we rolled out a massive program of workshops - including about 10 workshops on using Zoom in a single week." And "I was ... involved in supporting some of the numerous training sessions that took place to teach academic staff how to use [technology] in a way which supports active learning...

\section{Transition to online learning}

Educational designers identified their most significant contribution as helping academics successfully transition and migrate their learning and teaching activities to online (Figure 2). Whilst some reported this has manifested into providing rudimentary technical support, checking units for copyright compliance and fixing broken links, others spoke of novel opportunities to flex creative muscles that had otherwise remained dormant, for example:

[I was able to come] up with creative ideas for keeping students engaged online in otherwise very practice-based areas such as music, dance, acting, musical theatre and stage combat. Therefore, a large amount of this work was about being very inventive with the use of Zoom and the running of synchronous classes, as well as student use of video or audio recording to perform and receive feedback. 


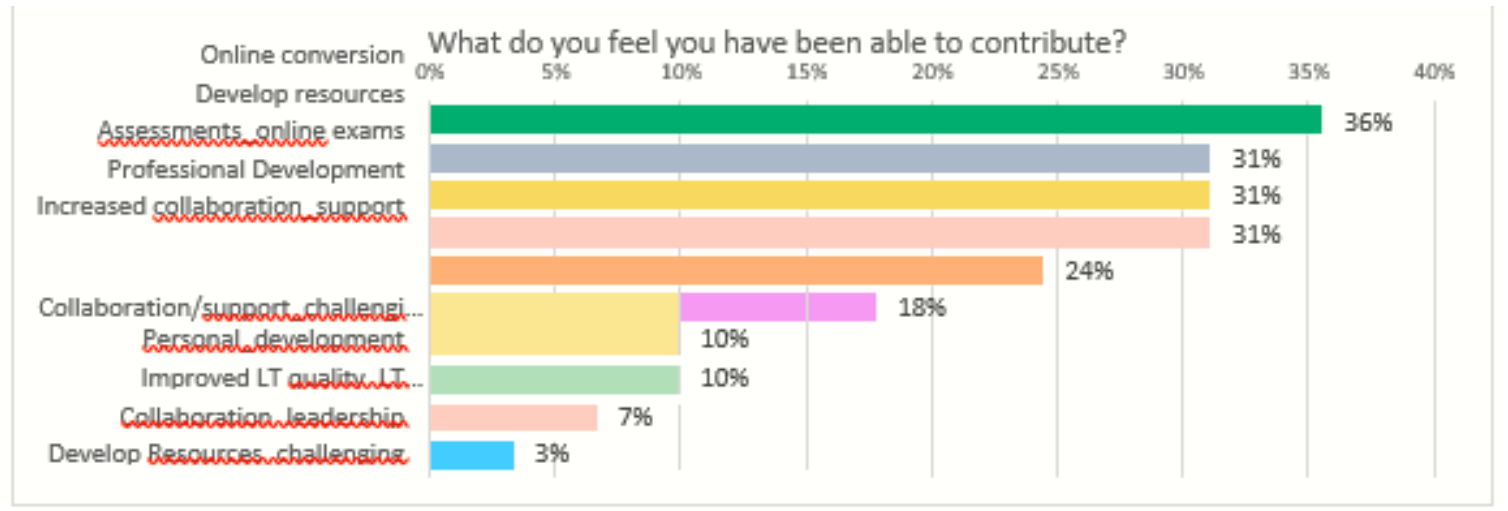

Figure 2. Where participant contributed most

Many spoke of and deemed the transition to online as positive, offering new opportunities for academic staff to take a closer look at their assessment and teaching practices, "thus allowing Learning Designers to recommend higher level question design in assessment tasks, increased use of peer feedback and greater implementation of marking guides and rubrics." Others explained that online migration was primarily focused on altering assessments to ensure they would be viable online. Indeed, these changes were necessary to replace practical oncampus assessments, laboratory work and invigilated examinations. On the last note, one respondent felt their contributions have helped academic staff to realise that invigilated examinations are not the only way to assess knowledge and, thus, have "been willing to explore future assessment changes rather than move back to invigilated exams." Essentially, designers have helped to redesign assessment, scaffold learning activities toward assessment and learning outcomes, and how those online learning activities can be facilitated in an engaging manner. Such work has involved educational designers ensuring that the focus remain on the quality of learning and teaching as a means "to avoid bad decisions being made in the transition to online teaching."

There were also some suggestions that designers needed to adopt a pastoral care role in their work with and support of academics during the online migration, with one respondent noting, "... helping academics cope with the massive change." Another respondent explained that they have offered staff workshops to teaching teams, programmes and discipline groups about resilient teaching design for future semesters. One summarised the work of the educational design team as a combination of counselling and consultation as some academics were clearly out of their comfort zone: "From the counselling lens, it was the concern convenors had for the students and how they were going to cope, what could, should convenors say to students. There was much reassuring to be done for the convenor and the students. Once anxieties were settled (or under control) came the education/pedagogical consultation, looking at what can be, what can the convenor do..."

Some designers have provided significant input into institutions' digital learning agenda, explaining that they have been "called to provide advice across the university, not just in our faculty." This is primarily because there is one only a handful of staff with any experience and qualifications with designing online learning. Although, in being called upon to offer strategic advice, some acknowledge they themselves have had to upskill and increase their knowledge of online pedagogy: "I am now much more adept with teaching online and am able to make suggestions about innovative uses of technologies appropriate to particular needs and contexts." One participant recalled how such an advisory role involved reassuring academics that "online teaching and assessment was not something new and untried; it had been in routine use for decades." Others have discovered opportunities to develop new research projects in the various aspects of online teaching and learning.

By contributing to this work, educational designers have discovered a renewed sense of purpose and increased recognition. Given the need to migrate courses online, many academic and fellow professional staff have come to recognise the value of educational designers and their ability to contribute to the ongoing need for online learning and teaching. This has been acutely significant, as noted by one respondent, in shaping "a workstream of academic innovation being a minimum standard of teaching online." This is not confined to the current times, with some highlighting their work will help to form a future institutional standard. Further, a small percentage of respondents detailed that being needed increased opportunities for collaboration and has made others appreciate their role, while others reported having to fight to work with staff to improve teaching that often resulted "in the role becoming diffused and more about a person's pet project." In contrast, respondents reported that academics now have a better understanding of what their roles entailed and how they can assist them in their teaching: 
I think pre-COVID, most academics thought that we were people that could teach them how to use technology, I feel that people now know that we can help them with much more than that. Instead of asking, "How do I use ZOOM?", the questions are now, "How would you suggest I redesign the end of semester exam in this subject?"

For some respondents, they are no longer perceived as merely a form of technical support. Rather, they are now valued for their pedagogical expertise and input. Admiration has also been expressed by the highest office in higher education, with Vice-Chancellors commenting on the contribution of educational designers. Thus, as one respondent described, "it feels like the role's profile had been lifted and more importantly, recognised."

\section{Emotions}

In responding, participants expressed a range of emotions. 14 (16\%) conveyed particularly negative sentiments (Figure 4). For these respondents it was apparent that the process of rushing to convert teaching to online had led a few to feel professionally and personally abused by unreasonable demands and perceived deficient institutional processes. In particular, they felt at the mercy of academics' emotional responses to technical difficulties and changing priorities. Given that educational designers appear to be directly supporting academics' technical adoption during the pandemic, some are bearing the brunt of academics' frustrations and anxiety:

"I am supporting academics who have not kept up with technology and have become the help desk and punching bag for their frustrations at having to learn new skills even though they are well paid to learn them." And, "Professionally, I have had to deal with very stressed academics who weren't so polite to us. Some of them were really anxious and wanted quick solutions for their issues."

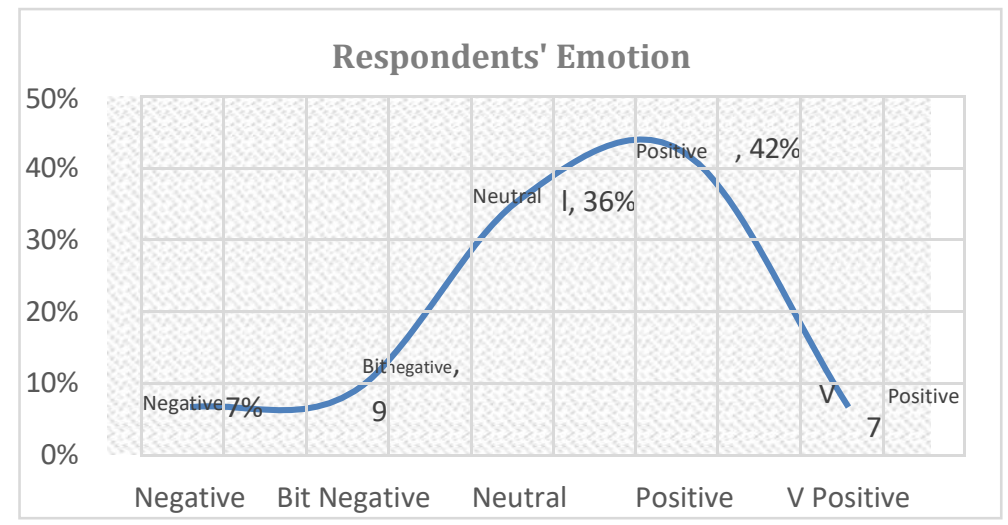

Figure 3. Distribution of emotional sentiment

Considering that designers are mainly working on providing solutions, one respondent felt they were a lifeline for academics who felt crushed by the enormity of their workloads and the tsunami of information being sent to them. They described feeling like they were in an emergency room performing triage. Similarly, others discussed the necessity of virtual handholding when working with academics. This caused some to become particularly resentful at academics' perceived lack of technical skills or unwillingness to develop those skills.

Others, understanding of academics' increased stress levels, felt weathered due to institutional factors such as inconsistence and rapidly changing policies, as seen in these comments: "The constantly changing nature of directives from the University means that I've had to spend more of my time trying to determine the truth and reality of new policies or processes for learning." And, "We also found it challenging to assist academics when the target kept moving (i.e., starting online, switching to 'in person' for week 2 or 3 , but then suddenly completely online)." They are also critical of their institutions perceived failure to embrace online teaching before the pandemic, as seen here: "Our institution has had to play "catch up" to even contemplate putting courses online as it had decided in the last couple of years that it is going to specialise in an elite face to face experience for students and key people were intent on dismantling any online courses that still existed."

Consequently, some were sceptical of their institution's understanding and implementation of online learning. Certain respondents spoke of enforced online migration in the context of pedagogical dumbing-down, arguing 
that the remote emergency teaching currently occurring does not reflect pedagogically sound design: For example, "it's very frustrating, tiring and non-productive as student engagement is lost as the online transition has resorted to the easiest and quickest fix of recording their [academic's] voice over 50 PowerPoint slides that lasts two hours which may be good for a one-off class but not really suitable for a 12 week university course." However, on the up-side, close to half responded favourably to the dramatic changes brought about by COVID19; demonstrating the potential of online education, and display a positive professional or personal sentiment on the changes to their role and the duties they were called to perform. Some feel that the institutional response to the pandemic has created opportunities for professional growth with a chance to expand and learn new skills:

"Personally, I have learnt so many things in the past couple of months because we weren't using the advanced features for certain tools in the LMS so my personal knowledge has also expanded." And "my knowledge of online pedagogy was pretty average prior to COVID and I have learned a lot in these last few months! ...I am now much more adept with teaching online and am able to make suggestions about innovative uses of technologies appropriate to particular needs and contexts."

Others relished challenges that the pandemic presented, discovering that working from home allowed them to conduct "more workshops than usual on learning design." Respondents also spoke of an increased demand in their services, explaining there is "more demand to provide advice on best practice (e.g., use of LMS), policy in terms of online delivery ... and on ways to avoid issues when delivering online (using the LMS quiz tool)." Rather than being bogged down by technical requests, educational designers have observed improved engagement in pedagogical discussions with academics.

Many also gained professional satisfaction from listening to, reassuring and guiding academic staff. By doing so, educational designers have been able to increase their professional network, "support more academics, respond quickly to their needs, and build different types of relationships with people." Thus, in supporting academics to transition to online learning, there have been opportunities to mentor and coach staff leading to more meaningful impact. Accounts also suggest that educational designers are often operating as an initial or only point of contact regarding technical and pedagogical issues. Consequently, they may be providing much needed pastoral care support for academic staff that exceeds their expertise and job description:

"I have supplied a degree of pastoral care in that I have established rapport, conveyed a sense of care and support, provided solutions and understanding." And "I feel I've been able to contribute a sense of calm when working individually with academics - a positive approach that we'll get through this and learn something in the process."

Several exhibited a sense of pride in recounting the ways in which they've been able to contribute to academics' well-being, arguing that strengthened relationships has increased their credibility and professional worth amongst academics. One respondent felt, rather than separate, they belonged to "a community of academics and those who support learning and teaching." Many are pleased with increased opportunities to collaborate with academics and have been able to carve out positions as leaders and mentors, stating "I was able to initiate more collaborative opportunities with other centres and focused more on reducing other people's stress and finding ways to support them in their duties and in their learning to get everyone through to the end of the semester."

\section{Conclusion}

This study provides an initial snapshot into the ways in which educational designers have been impacted by responding to an unfolding crisis. Whilst it appears that emergency online migration is fracturing academics' personal and professional lives (Watermeyer et al., 2020), it may be offering new opportunities for educational designers. Previously, educational designers reported difficulties in partnering with academics but are now enjoying more meaningful collaborative relationships. Further, educational designers are not only contributing systematic knowledge and intellectual capital for successful online migration but are upskilling academic staff and providing much needed pastoral care support. The crisis is undeniably delivering devastating effects for the sector but is also assisting educational designers in being gradually recognised as higher-level professionals who possess specialised skills and one of universities' most valuable assets. However, there is some concern that educational designers, in responding to the current and surmounting technical difficulties experienced by academics, may struggle to progress from a fixed understanding of their role "as technical-professional" (Bisset, 2018, p. 85). Bisset (2018) argues that there is less need for educational designers to possess technical expertise, which may not align with institutional priorities and responses to COVID-19. Nevertheless, there is clearly an 
evolving need for those with expertise in digital and student-centred pedagogies. Thus, in accordance with Campbell et al. (2005) assertions, educational designers may find greater agency and professional standing that goes beyond a mere technical one. It is envisioned they will occupy spaces to challenge and shape institutional discourses as to what online learning means and collaboratively develop more robust and resilient digital strategy before disaster strikes. Finally, this study provides weight to the needed assertion that, in the midst of significant upheaval, committed research on educational designers' emotions and how they make sense of change is warranted as a means to acknowledge the profession as a moral practice (Campbell et al., 2005).

\section{References}

Ayebi-Arthur, K. (2017). E-learning, resilience and change in higher education: Helping a university cope after a natural disaster. E-learning and Digital Media, 14(5), 259-274.

Baytiyeh, H. (2018). Online learning during post-earthquake school closures. Disaster Prevention and Management, 27(2), 215-227.

Berrett, Dan. (2016). Instructional Design: Demand growth for a new breed of academic. The Chronicle of Higher Education. 29 February.

Bisset, D. (2018). Role of Educational Designers in Higher Education Institutions. In C. Bossu, \& N. Brown (Eds.), Professional and Support Staff in Higher Education. (pp. 71-89). Springer Nature Singapore Pty Ltd.

Burki, T.K. (2020). COVID-19: Consequences for higher education. The Lancet Oncology, 21(6), 758. Brown, M., McCormack, M., Reeves, J., Brooks, C., Grajek, S., Alexander, B., Bali, M., Bulger, S., Dark, S.,

Engelbert, N., Gannon, K., Gauthier, A., Gibson, D., Gibson, R., Lundin, B., Veletsianos, G., \& Weber, N. (2020). EDUCAUSE Horizon Report, Teaching and Learning Edition. EDUCAUSE, Louisville, $\mathrm{CO}$.

Campbell, K., Schwier, R.A., \& Fenny, R.F. (2005). Agency of the instructional designer: Moral coherence and transformative social practice. Australasian Journal of Educational Technology, 21(2), 242-262.

Ching, Y.-H., Hsu, Y.-C., \& Baldwin, S. (2018). Becoming an online teacher: an analysis of prospective online instructors' reflections. Journal of Interactive Learning Research, 29(2), 145168.

Conole, G. \& Wills, S. (2013, Representing learning designs - making design explicit and shareable.

Educational Media International, 50(1), 24-38.

Czerniewicz, L., Trotter, H., \& Haupt, G. (2019). Online teaching in response to student protests and campus shutdowns: Academics' perspectives. International Journal of Educational Technology in Higher Education, 16(43), 1-22.

Duke, D. (2005). Hurricane Katrina's devastating effect on African-American higher education. The Journal of Blacks in Higher Education, 49, 56-63.

Dhawan, S. (2020). Online learning: A panacea in the time of COVID-19 crisis. Journal of Educational Technology Systems, O(0), 1-18.

Doucet, A., Netolicky, D., Timmers, K., \& Tuscano, F.J. (2020). Thinking about pedagogy in an unfolding pandemic: An independent report on approaches to distance learning during COVID19 school closures. https://issuu.com/educationinternational/docs/2020_research_covid19_eng

Fawns, T., Jones, D., \& Aitken, G. (2020). Challenging assumptions about "moving online" in response to COVID-19, and some practical advice. MedEdPublish, 1.

Fazackerley, A. (2020) Forget freshers' week: universities prepare to teach new first years online, The Guardian 3rd April. Available at: https://www.theguardian.com/education/2020/apr/03/forgetfreshers-week- universities-prepare-to-teach-new-first-years-online (Accessed: 25 April 2020).

Gibbs, R.G. (2007). Analyzing Qualitative Data. Sage Publications Ltd. London. DOI: https://dx.doi.org/10.4135/9781849208574.n4

Houlden, S., \& Veletsianos, G. (2019). A posthumanist critique of flexible online learning and its "anytime anyplace" claims. British Journal of Educational Technology, 50(3), 1005-1018.

Johnson, N., Veletsianos, G., \& Seaman, J. (2020). U.S. faculty and administrators' experiences and approaches in the early weeks of COVID-19 pandemic. Online Learning, 24(2), 6-21.

Kirk, A. (2020). COVID-19 unfolding in higher education. Journal of Paramedic Practice, 12(6), 219-219. Lorenzo, G. (2008). The Sloan semester. Journal of Asynchronous Learning Networks, 12(2), 5-40.

Mackey, J., Gilmore, F., Dabner, N., Breeze, D., \& Buckley, P. (2012). Blended learning for academic resilience 
in times of disaster or crisis. Journal of Online Learning and Teaching, 8(2), 122-132.

North, C. (2019). SHIFT: Learning designers as agents of change. In A.P. Correia (Ed.), Driving educational change: Innovations in action (pp. 38-51). Columbus, Ohio: Pressbooks.

Nicholas, M., \& Meuleman, N. (2017). Reflections of a new educational designer. Journal of Open, Flexible and Distance Learning, 21(2), 31-43.

Pevneva, I., \& Edmunds, P. (2020). Online learning vs. extreme learning in mining higher education under COVID. E3S Web of Conferences, 174, 1-6.

Rapanta, C., Botturi, L., Goodyear, P., Guardia, L., \& Koole, M. (2020). Online university teaching during and after the COVID-19 crisis: Refocusing teacher presence and learning activity. Postdigital Science and Education, 1(1), 1-23.

Ritzhaupt, A., \& Kumar, S. (2015). Knowledge and skills needed by instructional designers in higher education.

Performance Improvement Quarterly, 28(3), 51-69.

Seeto, D., \& Herrington, J.A. (2006). Design-based research and the learning designer. Proceedings of the 32rd annual ASCILITE conference: Who's learning? Whose technology? 741-745.

Shwier, R.A., Campbell, K., \& Kenny, R. (2004). Instructional designers' observations about identity, communities of practice and change agency. Australian Journal of Educational Technology, 20(1): $69-100$.

Tesar, M. (2020). Towards a post-COVID-19 'new normality'?: Physical and social distancing, the move to online and higher education. Policy Futures in Education, 18(5), 556-559.

Todorova, N., \& Bjorn-Anderson, N. (2011). University learning in time of crisis: The role of IT. Accounting Education: An international journal, 20(6), 597-599.

Watermeyer, R., Crick, T., Knight, C., \& Goodall, J. (2020). COVID-19 and digital disruption in UK universities: Afflictions and affordances of emergency online migration. Higher Education, 1-19.

Bellaby, A., Sankey, M. \& Albert, L. (2020). Rising to the occasion: Exploring the changing emphasis on educational design during COVID-19. In S. Gregory, S. Warburton, \& M. Parkes (Eds.), ASCILITE's First Virtual Conference. Proceedings ASCILITE 2020 in Armidale (pp. 145-155). https://doi.org/10.14742/ascilite2020.0137

Note: All published papers are refereed, having undergone a double-blind peer-review process.

The author(s) assign a Creative Commons by attribution licence enabling others to distribute, remix, tweak, and build upon their work, even commercially, as long as credit is given to the author(s) for the original creation.

(c) Bellaby, A., Snakey, M. \& Albert, L. 2020 